\title{
Impact of inhalational exposure to ethanol fuel on the pharmacokinetics of verapamil, ibuprofen and fluoxetine as in vivo probe drugs for CYP3A, CYP2C and CYP2D in rats
}

\author{
Juciane Lauren Cavalcanti Cardoso ${ }^{a}$, Vera Lucia Lanchote ${ }^{a}$, Maria Paula Marques Pereira ${ }^{a}$, \\ Jorge Manuel Vieira Capela ${ }^{\mathrm{b}}$, Natália Valadares de Moraes ${ }^{\mathrm{c}}$, José Salvador Lepera ${ }^{\mathrm{c}, *}$ \\ a Departamento de Análises Clínicas, Toxicológicas e Bromatológicas, Faculdade de Ciências Farmacêuticas de Ribeirão Preto, Universidade de São Paulo, \\ Brazil \\ b Departamento de Físico-Química, Instituto de Química, Universidade Estadual Paulista, Brazil \\ ${ }^{c}$ Departamento de Princípios Ativos Naturais e Toxicologia, Faculdade de Ciências Farmacêuticas, Universidade Estadual Paulista, Brazil
}

\section{A R T I C L E I N F O}

\section{Article history:}

Received 26 May 2015

Received in revised form

23 June 2015

Accepted 1 August 2015

Available online 8 August 2015

\section{Keywords:}

Ethanol fuel

Inhalation

Pharmacokinetics

CYP3A

CYP2C

CYP2D

\begin{abstract}
A B S T R A C T
Occupational toxicology and clinical pharmacology integration will be useful to understand potential exposure-drug interaction and to shape risk assessment strategies in order to improve occupational health. The aim of the present study was to evaluate the effect of exposure to ethanol fuel on in vivo activities of cytochrome P450 (CYP) isoenzymes CYP3A, CYP2C and CYP2D by the oral administration of the probe drugs verapamil, ibuprofen and fluoxetine. Male Wistar rats exposed to filtered air or to $2000 \mathrm{ppm}$ ethanol in a nose-only inhalation chamber during (6 h/day, 5 days/week, 6 weeks) received single oral doses of $10 \mathrm{mg} / \mathrm{kg}$ verapamil or $25 \mathrm{mg} / \mathrm{kg}$ ibuprofen or $10 \mathrm{mg} / \mathrm{kg}$ fluoxetine. The enantiomers of verapamil, norverapamil, ibuprofen and fluoxetine in plasma were analyzed by LC-MS/MS. The area under the curve plasma concentration versus time extrapolated to infinity $\left(A U C^{0-\infty}\right.$ ) was calculated using the Gauss-Laguerre quadrature. Inhalation exposure to ethanol reduces the AUC of both verapamil (approximately 2.7 fold) and norverapamil enantiomers ( $>2.5$ fold), reduces the $\mathrm{AUC}^{0-\infty}$ of $(+)-(\mathrm{S})$-IBU (approximately 2 fold) and inhibits preferentially the metabolism of $(-)-(\mathrm{R})$-FLU. In conclusion, inhalation exposure of ethanol at a concentration of 2 TLV-STEL ( $6 \mathrm{~h} /$ day for 6 weeks) induces CYP3A and CYP2C but inhibits CYP2D in rats.
\end{abstract}

(c) 2015 Elsevier Ltd. All rights reserved.

\section{Introduction}

Ethanol is among the chemicals of great importance for the human occupational exposure in terms of volume produced and the extent of its distribution. It is estimated that more than 650,000 workers are potentially exposed to ethanol mainly by inhalation

Abbreviations: ACGIH, American Conference of Governmental Industrial Hygienists; $\mathrm{AUC}^{0-\infty}$, area under the curve plasma concentration versus time over the infinite time interval; $\mathrm{Cl} / \mathrm{F}$, apparent total clearance; CYP, cytochrome $\mathrm{P} 450$; $\mathrm{EtOH}$, ethanol; FLU, fluvastatin; IBU, ibuprofen; LC-MS/MS, liquid chromatography coupled to tandem mass spectrometry; NOR, norverapamil; TLV-STEL, threshold limit value - short-term exposure limit; VER, verapamil.

* Corresponding author. Departamento de Princípios Ativos Naturais e Toxicologia, Faculdade de Ciências Farmacêuticas, Universidade Estadual Paulista, Rodovia Araraquara Jaú, Km 1, Campus da UNESP, 14801-902 Araraquara, SP, Brazil.

E-mail address: salvadorlepera@gmail.com (J.S. Lepera). but also by dermal route. Beyond the alcoholic beverages, the major industrial uses of ethanol are as solvent, as disinfectant, as intermediate in the synthesis of other chemicals and increasingly as biofuel (Anses, 2013; Bevan et al., 2009). Occupational exposure limits for ethanol are consistent around the world (Bevan et al., 2009). The American Conference of Governmental Industrial Hygienists (ACGIH) recommends a threshold limit value - short-term exposure limit (TLV-STEL) of $1880 \mathrm{mg} / \mathrm{m}^{3}$ (or $1000 \mathrm{ppm}$ ) to protect from respiratory, ocular irritation as well as long-term effects of ethanol vapor exposure (ACGIH, 2011). Ethanol is classified as a confirmed animal carcinogen with unknown relevance to humans (A3) by ACGIH. On the other hand, alcoholic beverages are classified as category 1 by the International Agency for Research on Cancer (IARC) due to sufficient evidence for carcinogenicity in humans. These different classifications are mainly based on different routes of exposure (inhalation versus oral), frequency and extent of 
exposure. It is estimated that exposure by inhalation to $1000 \mathrm{ppm}$ for $8 \mathrm{~h}$ would be equivalent to the consumption of $12 \mathrm{~g}$ orally in $8 \mathrm{~h}$ in terms of amount absorbed, which means negligible increase of risk carcinogenesis (Bevan et al., 2009; ACGIH, 2011).

Hepatic metabolism is responsible for the elimination of approximately $90 \%$ of ethanol, and is dependent mainly on alcohol dehydrogenase. Catalase and the microsomal cytochrome P450 (CYP) also contribute to ethanol metabolism, but in a lesser extent. The contribution of catalase and CYP isoforms to ethanol metabolism can increase in the presence of high amounts of $\mathrm{H}_{2} \mathrm{O}_{2}$ and after chronic alcohol consumption, respectively (Bruckner et al., 2013). Studies using human liver microsomes reported that CYP1A1, CYP1A2, CYP1B1, CYP2B6, CYP2C8, CYP2C9*1, CYP2C9*2, CYP2C9*3, CYP2C19, CYP2D6, CYP2E1, CYP2J2, CYP3A4 and CYP4A11 convert ethanol in acetaldehyde with apparent $K_{m}$ values around $10 \mathrm{mM}$. The selective inhibition of CYP2C9, CYP2C19, CYP2E1, CYP3A4 e CYP1A2 reduces ethanol oxidation in $8 \pm 1.2 \%$, $7.6 \pm 1.6 \%, 11.9 \pm 2.1 \%, 19.8 \pm 1.9 \%$ and $16.3 \pm 3.9 \%$, respectively (Hamitouche et al., 2006).

The effect of ethanol exposure through inhalation on cytochrome P450 isoenzymes activity is not fully understood. In human lymphoblastoid microsomes, $0.1-1 \%$ ethanol inhibits CYP1A1 (19-69\%), CYP2B6 (25-80\%), CYP2C19 (28-72\%) and CYP2D6 (11-59\%) (Busby et al., 1999). Ethanol at $1 \%$ inhibited phenacetin Odeethylation (CYP1A) in rat liver microsomes by $>20 \%$ (Li et al., 2010). Ethanol increased the $\mathrm{K}_{\mathrm{m}}$ and decreased the intrinsic clearance of CYP2B6-mediated bupropion hydroxylation and of CYP2C8mediated paclitaxel hydroxylation, in a concentration-dependent manner in human liver microsomes (Vuppugalla et al., 2007). Inhalation of ethanol vapors in high concentrations, enough to produces blood ethanol levels of $1.8 \mathrm{~g} / \mathrm{L}$, for 4 weeks, induced CYP2E1 in rats (Zerilli et al., 1995). The induction of CYP2E1 by chronically consumers of alcoholic beverages results in accelerated metabolism of many CYP2E1 substrates, such as paracetamol, halothane and chlorzoxazone. Thus, decreased drug efficacy of CYP2E1 substrates or the accumulation of its active metabolites are usually observed in patients chronically consuming ethanol (Klotz and Ammon, 1998).

The objective of the present study is to investigate the influence of exposure to ethanol fuel in a nose-only inhalation chamber on the pharmacokinetics of the verapamil, ibuprofen and fluoxetine enantiomers as biomarkers of in vivo activity of CYP3A, CYP2C and CYP2D, respectively, in rats. The integration of occupational toxicology with clinical pharmacology will be useful to understand the solvent-drug interaction and to shape risk assessment strategies in order to improve occupational health (Flack and Nylander-French, 2012).

\section{Material and methods}

\subsection{Chemicals}

Verapamil hydrochloride, norverapamil and ibuprofen were obtained from Sigma-Aldrich (St. Louis, USA). Racemic fluoxetine was from Toronto Research Chemicals (Toronto, Canada). Acetonitrile, hexane, isopropanol and ethanol high-performance liquid chromatography (HPLC) grade solvents were from Tedia Way (Fairfield, USA); methanol HPLC grade was from Merck (Darmstadt, Germany) and diisopropyl ether was from Acros Organics (New Jersey, USA). Deionized water used during experiments was obtained from a Milli-Q Plus Purification system (Millipore, Belford, MA, USA). One single batch of ethanol fuel (92.6-93.8\% ethanol) was purchased from a local gas station.

\subsection{Nose-only inhalation chamber}

The nose-only inhalation chamber was built in stainless steel (Fig. 1). The inner chamber receives the experimental atmosphere upward and distributes it radially toward the doors of exposure. The outer chamber exhausts the air which was not inhaled by the animals and the exhaled air. Every door of exposure is coupled to acrylic containers for the animals to be exposed only through the nose. The generation of the experimental atmosphere is performed by a continuous flow device in which compressed air stream is divided into two streams. The first is directed to a bubbler with distilled water in order to restore the humidity while second receives a constant flow of the solvent. These two streams are then recombined and whirled before entering the exposure chamber. The chamber has 44 doors, and the samples to monitoring the experimental atmosphere were collected at two diametrically opposed doors, one for each of the two planes of the chamber (top and bottom). The flow of ethanol fuel in the infusion pump was adjusted in order to produce a controlled atmosphere of ethanol of $2000 \mathrm{ppm}$, which corresponds to 2-fold the TLV-STEL recommended by ACGIH. Before experiments, the generation of the controlled atmosphere of ethanol was validated by checking the fluctuations of ethanol concentration between doors (homogeneity) and over time during a cycle of 6 -h exposure (stability). Air samples were collected during initial $15 \mathrm{~min}$ in the first, third and sixth hours of ethanol exposure.

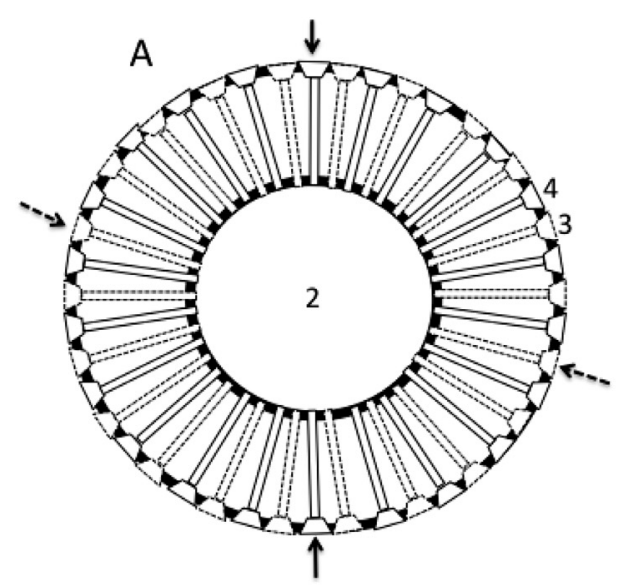

B

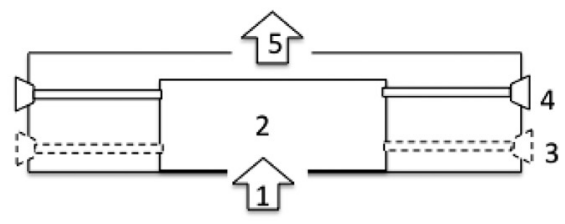

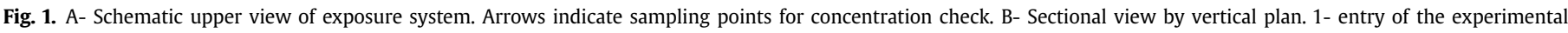
atmosphere; 2- Inner distribution chamber; 3- exposure ports of the lower plane (dotted line); 4- exposure doors of the upper plane (solid line); 5- exhaust. 


\subsection{Analysis of ethanol by gas chromatography-flame ionization detector}

Ethanol concentrations in air samples were analyzed by gaschromatography with flame ionization detection according to NIOSH Method 1400, with little modification (Niosh, 1994). Briefly, samples were collected in tubes $100 \times 50 \mathrm{mg}$ of active charcoal, using sampling pumps (SKC ${ }^{\circledR}$ Inc, Eighty Four, PA, USA) and desorbed in carbon disulfide (Merck, Rio de Janeiro) containing nbutanol $(1 \mu \mathrm{l} / \mathrm{ml})$ as internal standard. Samples were injected into a gas chromatograph equipped with CG500 Carbowax $20 \mathrm{M}$ column with Chromossorb WHP $1.8 \mathrm{~m}$ (Scientific Instruments Ltd. CG), and flame ionization detector. The temperatures of column oven, vaporizer and detector were $120^{\circ} \mathrm{C}$ (isothermal mode), $200{ }^{\circ} \mathrm{C}$ and $220^{\circ} \mathrm{C}$, respectively.

\subsection{Animals}

The experimental study was approved by the Ethics Committee for the Use of Animals of the Faculdade de Ciências Farmacêuticas de Araraquara, Universidade Estadual Paulista (Araraquara, SP, Brazil, protocol FCF/CAr 39/2008). The animals were treated in accordance with the Guide for the Care and Use of Laboratory Animals adopted by the Brazilian Association for Laboratory Animal Science. Male Wistar rats, provided by the University Central Animal House, in Botucatu, Brazil, weighting $250 \pm 10 \mathrm{~g}$ were kept at $20 \pm 1{ }^{\circ} \mathrm{C}, 60 \pm 20 \%$ relative humidity and a 12 -h light-dark cycle. The animals had free access to rat chow and water, except $12 \mathrm{~h}$ before the administration of the investigated drugs.

Animals were divided in 6 groups: three groups were exposed to filtered air (control groups) and three groups exposed to $2000 \mathrm{ppm}$ ethanol fuel, equivalent to 2 -fold TLV-STEL in a nose-only inhalation exposure chamber for 6 h/day, 5 days/week during 6 weeks.

On the last day of exposure, the animals received a single oral administration of racemic verapamil, ibuprofen or fluoxetine control, according to the following experimental protocol. The drug concentration in the solution administered to each animal was adjusted in order to achieve administration equivalent to $1 \mathrm{ml} / \mathrm{kg}$ of body weight. The maximum of three blood samples were collected at different times from each rat ( $\mathrm{n}=8$, for each sampling time), by excision of about $2 \mathrm{~mm}$ from the distal portion of the tail, after localized vasodilation by heating at $42{ }^{\circ} \mathrm{C}$. After centrifugation, plasma samples were stored at $-20^{\circ} \mathrm{C}$ until analysis.

\subsubsection{Verapamil treatment control group (VER control) and group exposed to ethanol fuel + verapamil}

Before the last exposure to air (VER Control) or ethanol fuel (VER + EtOH), animals ( $\mathrm{n}=32$ per group) were fasted for $12 \mathrm{~h}$ and were orally treated by gavage with $10 \mathrm{mg} / \mathrm{kg}$ racemic verapamil dissolved in water by gavage (Mateus et al., 2007). Blood samples were collected at times $0.33,0.67,1,1.5,2,2.5,3,3.5,4,4.5,5$ and $6 \mathrm{~h}$ after the administration of the drug.

\subsubsection{Ibuprofen control group (IBU control) and group exposed to ethanol fuel + ibuprofen $(\mathrm{IBU}+\mathrm{EtOH})$}

Before the last exposure to air (IBU Control) or ethanol fuel (IBU + EtOH), animals ( $\mathrm{n}=22$ per group) were fasted for $12 \mathrm{~h}$ and received orally $25 \mathrm{mg} / \mathrm{kg}$ racemic ibuprofen dissolved in polyethylene glycol:saline solution $(70: 30 \mathrm{v} / \mathrm{v})$ by gavage (Teng et al., 2003; Newa et al., 2008). Blood samples were collected at 0.25 , $0.5,1,2,4,6,7$ and $8 \mathrm{~h}$.

\subsubsection{Fluoxetine control group (FLU control) and group exposed to ethanol fuel + fluoxetine $(\mathrm{EtOH}+\mathrm{FLU})$}

Before the last exposure to air (FLU Control) or ethanol fuel
$(\mathrm{FLU}+\mathrm{EtOH})$, animals $(\mathrm{n}=22$, per group) were fasted for $12 \mathrm{~h}$ and received orally $10 \mathrm{mg} / \mathrm{kg}$ racemic fluoxetine dissolved in polyethylene glycol:saline solution (70:30, v/v) by gavage (Hui et al., 2007; Upreti and Eddington, 2007). Blood samples were taken at times $0.25,0.5,1,2,3,4,6$ and $12 \mathrm{~h}$.

\subsection{LC-MS/MS analysis of verapamil and norverapamil enantiomers in rat plasma}

The analysis of verapamil (VER) and norverapamil (NOR) enantiomers in plasma was performed according to the method validated by Mateus et al. (Mateus et al., 2007). The lower limit of quantification was $1 \mathrm{ng} / \mathrm{ml}$ for verapamil and norverapamil enantiomer, and the calibration curves showed good linearity in the range $1-250 \mathrm{ng} / \mathrm{ml}$ for verapamil and norverapamil enantiomers. The coefficients of variation and relative errors were less than $15 \%$.

\subsection{LC-MS/MS analysis of ibuprofen enantiomers in rat plasma}

The enantioselective analysis of ibuprofen (IBU) enantiomers in plasma was performed according the method recently published by our research group (Cardoso et al., 2014). The method was linear in the range $0.025-50 \mu \mathrm{g} / \mathrm{ml}$ for each ibuprofen enantiomer, and the lower limit of quantification was $0.025 \mu \mathrm{g} / \mathrm{ml}$. The coefficients of variation and percentage of inaccuracy were less than $15 \%$.

\subsection{LC-MS/MS analysis of fluoxetine enantiomers in rat plasma}

The separation of fluoxetine (FLU) enantiomers in plasma was performed in an Astec Chirobiotic ${ }^{\circledR} \mathrm{V}$ column $(250 \times 4.6 \mathrm{~mm}, 5 \mu \mathrm{m}$ particles) and mobile phase consisted of ethanol: $15 \mathrm{mM}$ ammonium acetate $(85: 15 \%, \mathrm{v} / \mathrm{v})$, eluting at a flow rate of $1 \mathrm{ml} / \mathrm{min}$ (Cardoso et al., 2013). Calibration curves were constructed in the interval $0.5-500 \mathrm{ng}$ of each enantiomer per mililiter of rat plasma and the lower limit of quantification was $0.5 \mathrm{ng} / \mathrm{ml}$. The coefficients of variation and percentage of inaccuracy were less than $15 \%$.

\subsection{Pharmacokinetic and statistical analysis}

The area under the curve plasma concentration versus time over the infinite time interval $\left(A U C^{0-\infty}\right)$ was calculated using the Gauss-Laguerre quadrature. The corresponding concentrations at times that do not coincide with the nodes of the quadrature were estimated by polynomial interpolation (Amisaki, 2001). The apparent total clearance $(\mathrm{Cl} / \mathrm{F})$ was calculated by the equation $\mathrm{Cl}$ / $\mathrm{F}=$ dose $/ \mathrm{AUC}^{0-\infty}$ (Ritschel and Kearns, 1998).

Confidence intervals at 95\% level for the difference between the $\mathrm{AUC}^{0-\infty}$ and $\mathrm{Cl} / \mathrm{F}$ values were built for comparisons between enantiomers of each racemic drug and between groups (control versus ethanol exposed groups). The variances were estimated considering that the sampling is sparse, that is, samples may be collected from the same animal, but not at all sampling times (Capela et al., 2012).

\section{Results and discussion}

Interindividual variability in drug efficiency and drug safety remains a challenge in clinical pharmacology. The induction or inhibition of enzymes involved in metabolism due to physiological conditions, diseases, drug-drug interaction or occupational exposure to chemical agents are among the main causes of variability in drug response. The environmental or occupational exposure to chemicals can modulate the activity of cytochrome P450 isozymes. The enzyme induction and inhibition may affect the enantiomers of a chiral drug in different proportions when enantiomers are 
metabolized by different enzymes or the same enzyme at different rates. Although exposures to solvents are very frequent, in vivo studies that evaluate the influence of these exposures on pharmacokinetics are scarce (Karin, 1996; Kroemer et al., 1996; Mehvar and Reynolds, 1996; Ingelman-Sunderberg, 2001; Hutzler and Tracy, 2002).

The present study reports for the first time the influence of ethanol fuel inhalation ( $6 \mathrm{~h}$ /day, five days a week for 6 weeks) on the in vivo activities of CYP3A, CYP2C and CYP2D using verapamil, ibuprofen and fluoxetine, respectively, as probe drugs in rats. The level of exposure of $2000 \mathrm{ppm}$ of ethanol in the air chamber, which corresponds to 2-fold the TLV-STEL is not high enough to observe respiratory or ocular adverse effects in rats. Long-term effects of ethanol in animals (liver cirrhosis, impaired fertility and offspring development) were observed only at exposure concentrations greater than $10,000 \mathrm{ppm}\left(18.8 \mathrm{~g} / \mathrm{m}^{3}\right)$. Ethanol concentration in the air that causes respiratory irritation in mice is estimated to be

\section{3,000 ppm (ACGIH, 2011).}

Validation tests of the exposure chamber showed that ethanol concentrations between the individual chambers did not differ significantly, neither the mean concentrations calculated for 15min intervals during the $6 \mathrm{~h}$ of the experiments (data not shown). The advantages of nose-only exposure compared to wholebody exposure chambers is the use of less solvent and greater control over exposure, resulting in greater uniformity, and prevent the absorption of vapors automotive fuel in by oral or dermal routes (Holänder, 1988; Kennedy and Valentine, 1994).

Ethanol blood concentrations were not determined due to the limited blood sampling to the available analytical capacity and this is the main limitation of the present work. However, a physiologically based pharmacokinetic study in rats showed that steady state concentrations equivalent to $3.7 \mathrm{mg} / \mathrm{L}(80 \mu \mathrm{M})$ in blood were observed within the first $30 \mathrm{~min}$ and remained constant up to the $6 \mathrm{~h}$ exposure to $600 \mathrm{ppm}$ ethanol by inhalation (Pastino et al., 1997).
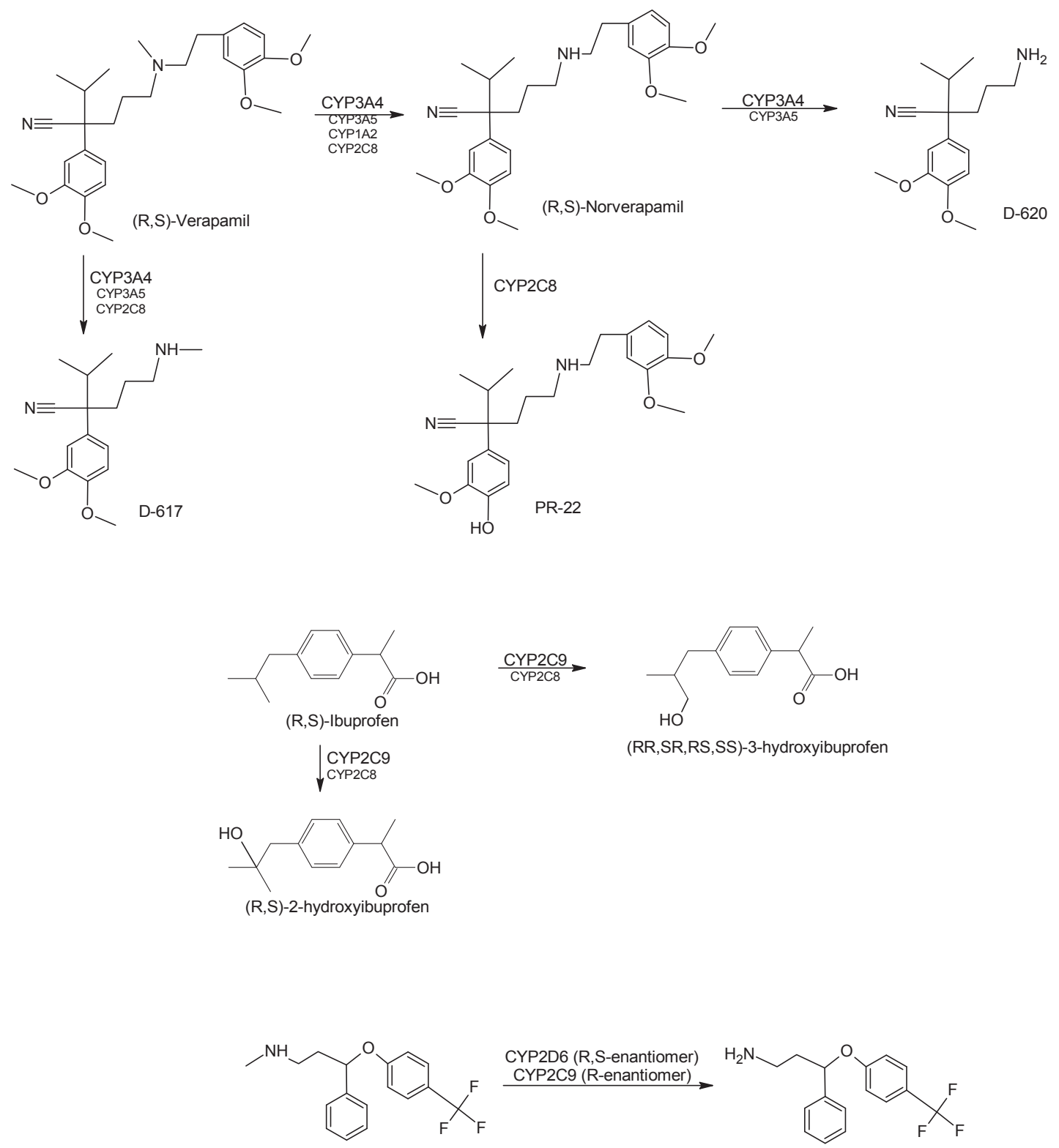

(R,S)-Fluoxetine

(R,S)-Norfluoxetine

Fig. 2. Metabolism of verapamil (Tracy et al., 1999), ibuprofen (Hamman et al., 1997) and fluoxetine enantiomers (Ring et al., 2001). 
Thus, assuming linear pharmacokinetics, concentrations of around $6.1 \mathrm{mg} / \mathrm{L}(133 \mu \mathrm{M})$ and $12.3 \mathrm{mg} / \mathrm{L}(267 \mu \mathrm{M})$ would be observed after exposures to 1000 and 2000 ppm ethanol in rats, respectively. These results are consistent with blood levels of $3 \pm 0.6 \mathrm{mg} / \mathrm{L}$ ethanol observed in men after $4 \mathrm{~h}$ exposure to ethanol $1050 \mathrm{ppm}$ (Dumas-Campagna et al., 2014).

Verapamil (VER), a calcium channel antagonist used in the treatment of arrhythmia, angina and hypertension, is a chiral compound marketed as a racemic mixture of the $(+)-(R)-$ and (-)-(S)-VER. In man, verapamil is essentially eliminated by $\mathrm{N}-$ demethylation and $\mathrm{N}$-dealkylation, with formation of norverapamil (NOR) and D-617, respectively. CYP3A4 is primarily responsible for $\mathrm{N}$-demethylation and N-dealkylation with formation of (R)-NOR and (S)-NOR and (R)-D-617 and (S)-D-617, although the CYP1A2 and CYP3A5 also contribute in a lesser extent (Tracy et al., 1999) (Fig. 2).

The enantiomeric $S / R$ ratios of verapamil and norverapamil in VER Control group with plasma accumulation of (-)-(S)-VER and $(-)-(S)-N O R$, are opposite to those observed in human studies. Accumulation of $(+)-(\mathrm{R})-\mathrm{VER}$ and $(+)-(\mathrm{R})-\mathrm{NOR}$ with $\mathrm{AUC}^{0-\infty}$ ratio $(\mathrm{R} / \mathrm{S})$ of $3.8 \pm 0.5$ for VER and 2.7 for NOR were observed after the administration of a single dose of $120 \mathrm{mg}$ racemic verapamil to healthy volunteers (Ho et al., 2000). The inconsistency between human and experimental data is due to the opposite stereoselectivity in plasma protein binding which results in opposite stereoselective unbound fractions in human $(S>R)$ and rats $(R>S)$ for both VER and NOR (Robinson and Mehvar, 1996; Bhatti and Foster, 1997).

Inhalation exposure to ethanol fuel reduces the $\mathrm{AUC}^{0-\infty}$ and increases the clearance of both verapamil enantiomers by approximately 2.7 times compared to the control group. Plasma accumulation of the eutomer (-)-(S)-VER with $A U C^{0-\infty}$ ratio S/R of 3.64 $\left(\right.$ AUC $^{0-\infty} 122.81 \mathrm{vs} 33.77 \mathrm{ng} \mathrm{h} \mathrm{ml}^{-1}$ ) was observed in the group exposed to ethanol fuel, similar to that observed for the control group (Fig. 3). These data suggest CYP3A induction whereas CYP3A4 is primarily responsible for N-dealkylation, although CYP1A2 and CYP3A5 also contribute in lesser extent (Tracy et al., 1999, Fig. 2). Our results are in agreement with in vitro studies using human CYP3A4 supersomes ${ }^{\mathrm{TM}}$ which showed that $1-4 \%$ ethanol induced CYP3A4 activity about 1.5-fold (Rokitta et al., 2013). Moreover, the $A U C^{0-\infty}$ of both norverapamil enantiomers was smaller in ethanol exposed group compared to the control
Table 1

Kinetic disposition of (-)-(S)-verapamil, (+)-(R)-verapamil (-)-(S)-norverapamil and $(+)-(\mathrm{R})$-norverapamil in rats exposed to ethanol by inhalation and controls ( $\mathrm{n}=8$, per sampling time). Data presented as means \pm standard deviation.

\begin{tabular}{|c|c|c|c|}
\hline & $\mathrm{AUC}^{0-\infty}\left(\mathrm{ng} \mathrm{h} \mathrm{m}{ }^{-1}\right)$ & $\mathrm{Cl} / \mathrm{F}\left(\mathrm{l} \mathrm{h}^{-1} \mathrm{~kg}^{-1}\right)$ & $\mathrm{AUC}_{(-)} / \mathrm{AUC}_{(+)}$ \\
\hline \multicolumn{4}{|l|}{ Control } \\
\hline (-)-(S)-verapamil & $333.95 \pm 54.39$ & $14.97 \pm 2.44$ & 3.64 \\
\hline$(+)$-(R)-verapamil & $91.84 \pm 23.86$ & $54.44 \pm 14.14$ & \\
\hline \multicolumn{4}{|l|}{ Ethanol group } \\
\hline (-)-(S)-verapamil & $122.81 \pm 24.54^{*}$ & $40.71 \pm 8.14^{*}$ & 3.64 \\
\hline \multicolumn{3}{|l|}{ Control } & \\
\hline (-)-(S)-norverapamil & $246.00 \pm 42.64$ & - & 2.30 \\
\hline $\begin{array}{l}(+)-(\mathrm{R}) \text {-norverapamil } \\
\text { Ethanol group }\end{array}$ & $106.97 \pm 21.78$ & - & \\
\hline (-)-(S)-norverapamil & $80.20 \pm 16.24^{*}$ & - & 1.85 \\
\hline$(+)-(\mathrm{R})$-norverapamil & $43.39 \pm 7.99^{*}$ & - & \\
\hline
\end{tabular}

${ }^{*} \mathrm{p}<0.05$ (control vs. ethanol group).

(Table 1). It is noteworthy that norverapamil is an intermediate metabolite, whose AUC value reflects not only its CYP3A-dependent formation as well as the consecutive metabolism to D-620 metabolite by CYP3A4, CYP3A5 and CYP2C8, or PR-22 metabolite by CYP2C8 (Tracy et al., 1999). In vitro experiments using HepG2 cell lines and in vivo studies in rats fed with ethanol-containing diet showed that ethanol induced CYP3A activity and content (Feierman et al., 2003). However, at 3\%, ethanol significantly inhibited cDNAexpressed CYP3A4 activity in human lymphoblastoid cell microsomes (Busby et al., 1999).

Ibuprofen (IBU) is a drug of the group of nonsteroidal antiinflammatory drugs marketed in racemic form (Itoh et al., 1997). The unidirectional chiral inversion of (-)-(R)-IBU to (+)-(S)-IBU occurs in humans, rats and other animal species (Kaiser et al., 1976; Knihinicki et al., 1989; Rudy et al., 1991; Sattari and Jamali, 1994). The metabolism of ibuprofen in humans occurs in two ways, that is CYP2C-mediated oxidation and conjugation with glucuronic acid and (Glowka and Karazniewicz, 2007).

Rats treated with ibuprofen (IBU Control) showed $A U C^{0-\infty} S / R$ ratio of 6 (Table 2), while Teng et al. (2003) and Sattari and Jamali (1994) reported S/R ratios of 3.27 and 3.62, respectively, in animals not subjected to the same stress conditions as the ones in the present study. The stereoselectivity might be related to the absorption rate following oral administration in rats, whereas the

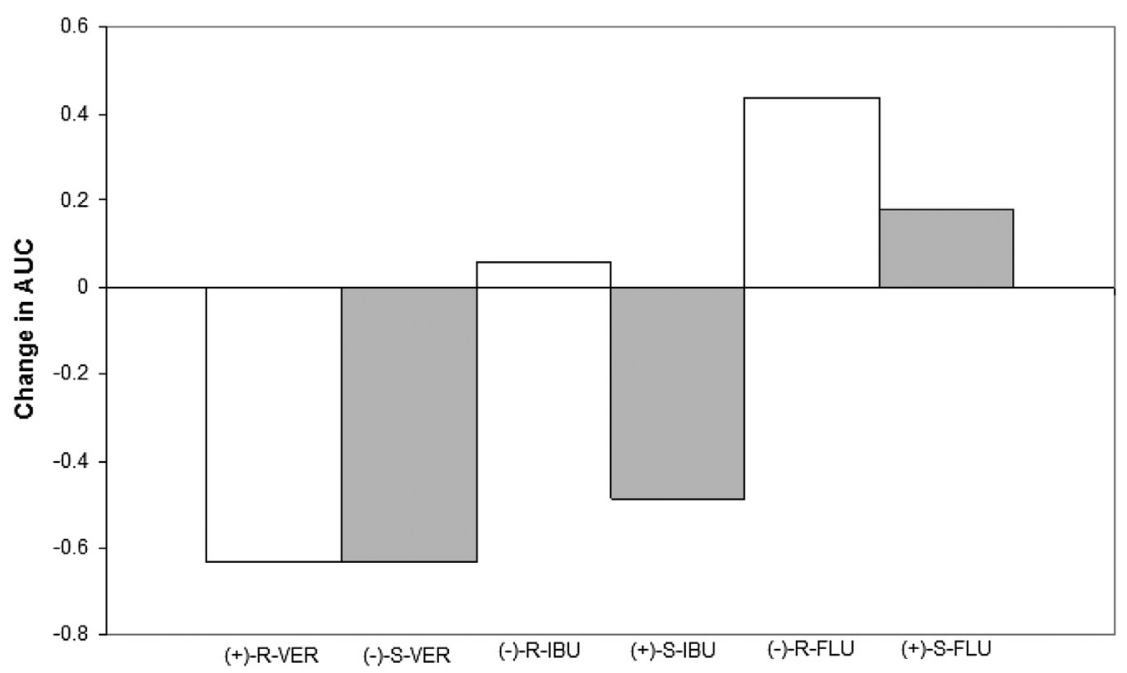

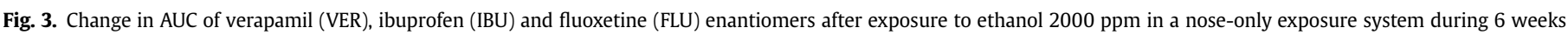
(6 h/day, 5 days/week) in rats. Data presented as averages. 
Table 2

Kinetic disposition of $(+)-(\mathrm{S})$-ibuprofen and $(-)-(\mathrm{R})$-ibuprofen in rats exposed to ethanol by inhalation, and controls ( $\mathrm{n}=8$, per sampling time). Data presented as means \pm standard deviation.

\begin{tabular}{lccl}
\hline & $\mathrm{AUC}^{0-\infty}\left(\mu \mathrm{g} \mathrm{h} \mathrm{ml}^{-1}\right)$ & $\mathrm{Cl} / \mathrm{F}\left(\mathrm{l} \mathrm{h}^{-1} \mathrm{~kg}^{-1}\right)$ & $\mathrm{AUC}_{(+)} / \mathrm{AUC}_{(-)}$ \\
\hline IBU Control & & & \\
(+)-(S)-ibuprofen & $140.98 \pm 13.21$ & $88.67 \pm 3.32$ & 6.00 \\
(-)-(R)-ibuprofen & $23.48 \pm 4.43$ & $532.31 \pm 40.16$ & \\
IBU + EtOH & & & \\
$(+)-(S)$-ibuprofen & $72.45 \pm 10.09^{*}$ & $172.54 \pm 9.62^{*}$ & 2.92 \\
$(-)$-(R)-ibuprofen & $24.81 \pm 3.71$ & $503.76 \pm 30.13$ & \\
\hline
\end{tabular}

* $\mathrm{p}<0.05$ (control vs ethanol group).

presystemic unidirectional inversion of $(-)-(\mathrm{R})-\mathrm{IBU}$ to $(+)-(\mathrm{S})-\mathrm{IBU}$ can occur in the intestinal cells (Sattari and Jamali, 1994).

The AUC ${ }^{0-\infty}$ and apparent total clearance observed in the control or in animals exposed ethanol fuel corroborate the unidirectional inversion of (-)-(R)-IBU to (+)-(S)-IBU (Table 2). Inhalation exposure to ethanol fuel significantly reduced the $A U C^{0-\infty}$ of the enantiomer (+)-(S)-IBU and increased by 2-fold its apparent clearance compared to control (Fig. 3). Considering that CYP2C9 accounts for $49-70 \%$ of $(+)-(S)-I B U$ total clearance but only $20-30 \%$ of (-)-(R)-IBU total clearance (Tornio et al., 2007; Chang et al., 2008), our findings suggest that inhalation exposure to ethanol fuel induces CYP2C9. In agreement with the present findings, evidences from clinical studies also show that the clearance of tolbutamide and phenytoin, both CYP2C9 substrates, were significantly increased in heavy consumers of ethanol during ethanol withdrawal (Iber, 1977; Sandor et al., 1981; Miners and Birkett, 1998).

Fluoxetine (FLU) is a selective serotonin reuptake inhibitor available as a racemic mixture for the treatment of depression (Wong et al., 1985; Margolis et al., 2000). In human liver microsomes, CYP2D6 and CYP2C9 contribute to the formation of the Ndemethylated metabolites (-)-(R)- and $(+)-(\mathrm{S})$-norfluoxetine (Ring et al., 2001). Plasma accumulation (AUC ${ }^{0-\infty} 650.91$ vs $386.48 \mathrm{ng} \mathrm{h} \mathrm{ml}{ }^{-1}$ ) and lower apparent clearance (7.68 vs $12.93 \mathrm{~L} \mathrm{~h}^{-1} \mathrm{~kg}^{-1}$ ) were observed for (+)-(S)-FLU compared to the $(-)-(R)-F L U$ in the FLU control group (Table 3). The plasma accumulation favoring (+)-(S)-FLU is in agreement with the study reported by Guo et al. (2002), although in the present study the animals were subjected to a stress condition by repeated restraint ( $6 \mathrm{~h} /$ day) for six weeks. The exposure to ethanol fuel did not alter the enantioselectivity of fluoxetine kinetic disposition maintaining the faster elimination of (R)-isomer than the (S)-isomer (Table 3). However, ethanol fuel inhalation preferentially inhibits the metabolism of the enantiomer (-)-(R)-FLU, probably due to CYP2D inhibition (Fig. 3). The intrinsic clearance for (R)-FLU and (S)-FLU are greater for CYP2D6, with secondary contributions of CYP2C9, CYP3A4 and CYP2C19 (Margolis et al., 2000). The clearance values of (-)-(R)-FLU and (+)-(S)-FLU differ among CYP2D6 extensive

\section{Table 3}

Kinetic disposition of $(+)-(S)$-fluoxetine and $(-)-(R)-$ fluoxetine in rats exposed to ethanol by inhalation and controls ( $\mathrm{n}=8$, per sampling time). Data presented as means \pm standard deviation.

\begin{tabular}{lccc}
\hline & $\mathrm{AUC}^{0-\infty}\left(\mathrm{ng} \mathrm{h} \mathrm{ml}^{-1}\right)$ & $\mathrm{Cl} / \mathrm{F}\left(\mathrm{l} \mathrm{h}^{-1} \mathrm{~kg}^{-1}\right)$ & $\mathrm{AUC}_{(+)} / \mathrm{AUC}_{(-)}$ \\
\hline FLU Control & & & \\
(+)-(S)-fluoxetine & $650.91 \pm 182.54$ & $7.68 \pm 4.64$ & 1.68 \\
(-)-(R)-fluoxetine & $386.48 \pm 130.90$ & $12.94 \pm 4.38$ & \\
FLU + EtOH & & & \\
(+)-(S)- fluoxetine & $766.05 \pm 103.38$ & $6.52 \pm 0.78$ & 1.38 \\
(-)-(R)- fluoxetine & $555.09 \pm 86.22^{*}$ & $9.01 \pm 1.40^{*}$ & \\
\hline
\end{tabular}

${ }^{*} \mathrm{p}<0.05$ (control $v s$ ethanol group). metabolizers ( 36 and $40 \mathrm{~L} / \mathrm{h}$ ) and poor metabolizers ( 3 and $17 \mathrm{~L} / \mathrm{h}$ ) (Fjordside et al., 1999). Thus, (-)-(R)-fluoxetine clearance is reduced to a greater extent than the corresponding (+)-(S)-FLU in poor metabolizers CYP2D6. In other words, the clearance of the enantiomer (-)-(R)-FLU appears to rely almost exclusively on CYP2D. Ethanol at 1\% inhibited the CYP2D activity (dextromethorphan O-demethylation) by nearly $36 \%$ in rat liver microsomes (Li et al., 2010).

The experimental data observed in the present work point out the impact of exposure-drug interaction in the pharmacokinetics of clinically available drugs. Further work requires epidemiological approach and/or the physiologically-based pharmacokinetics approach to confirm the impact of ethanol exposure in the followup of drug administration to workers chronically exposed.

\section{Conclusion}

In conclusion, ethanol fuel inhalation at a concentration of 2 TLV-STEL ( $6 \mathrm{~h}$ /day for 6 weeks) induced CYP2C in rats by reducing $\mathrm{AUC}^{0-\infty}$ and increasing the apparent clearance of the enantiomer (+)-(S)-ibuprofen; CYP2D inhibition indicated by the increased $\mathrm{AUC}^{0-\infty}$ and decreased apparent clearance of (-)-(R)-fluoxetine; and CYP3A induction as evidenced by reduced $A \mathrm{UC}^{0-\infty}$ values and increased apparent clearances of both verapamil enantiomers.

\section{Acknowledgments}

The authors acknowledge the financial support from São Paulo Research Foundation (Fundação de Amparo à Pesquisa do Estado de São Paulo, FAPESP) under grant number 2009/17532-0.

\section{Transparency document}

Transparency document related to this article can be found online at http://dx.doi.org/10.1016/j.fct.2015.08.002.

\section{References}

American Conference of Governamental Industrial Hygienists 2011 \& TLVs ${ }^{\circledR}$ and BEIs ${ }^{\mathbb{R}}$. Based on the Documentation of the Threshold Limit Values for Chemical Substances and Physical Agents and Biological Exposure Indices, 2011. CD-ROM Cincinnati.

Amisaki, T., 2001. Gaussian quadrature as a numerical integration method for estimating area under the curve. Biol. Pharm. Bull. 24, 70-77. Tokyo.

Anses, 2013. Assessing the Risks of Ethanol [Online]. Maison-Alfort, France. Available from: http://www.anses.fr/en/content/assessing-risks-ethanol. Last accessed: 05 Mar 2014

Bevan, R.J., Slack, R.J., Holmes, P., Levy, L.S., 2009. An assessment of potential cancer risk following occupational exposure to ethanol. J. Toxicol. Environ. Health B Crit. Rev. 12 (3), 188-205.

Bhatti, M.M., Foster, R.T., 1997. Pharmacokinetics of the enantiomers of verapamil after intravenous and oral administration of racemic verapamil in a rat model. Biopharm. Drug Dispos. 18 (5), 387-396. Chichester.

Bruckner, J.V., Anand, S.S., Warren, D.A., 2013. Toxic effects of solvents and vapors In: Casarett, L., Doull, J. (Eds.), Toxicology the Basic Science of Poison, eigth ed. Mc Graw Hill Education, New York, pp. 1031-1112.

Busby Jr., W.F., Ackermann, J.M., Crespi, C.L., 1999. Effect of methanol, ethanol, dimethyl sulfoxide, and acetonitrile on in vitro activities of c-DNA-expressed human cytochromes P-450. Drug Metab. Dispos. 27 (2), 246-249.

Capela, J.M.V., Capela, M.V., Lepera, J.S., 2012. Estimação da área sob a curva para dados farmacocinéticos obtidos por amostragem esparsa. In: $34^{\circ}$ Congresso Nacional de Matemática Aplicada e Computacional., Águas de Lindóia.

Cardoso, J.L. Lanchote, V.L., Pereira, M.P., de Moraes, N.V., Lepera, J.S., 2014. Analysis of ibuprofen enantiomers in rat plasma bt LC-MS/MS. J. Sep. Sci. 37, 944-949.

Cardoso, J.L., Lanchote, V.L., Pereira, M.P., Capela, J.M., Lepera, J.S., 2013. Influence of gasoline inhalation on the enantioselective pharmacokinetics of fluoxetine in rats. Chirality 25 (3), 206-210.

Chang, S.Y., Li, W., Traeger, S.C., Wang, B., Cui, D., Zhang, H., Wen, B., Rodrigues, A.D. 2008. Confirmation that cytochrome P450 2C8 (CYP2C8) plays a minor role in (S)-(+)- and (R)-(-)-ibuprofen hydroxylation in vitro. Drug Metab. Dispos. 36 (12), 2513-2522.

Dumas-Campagna, J., Tardif, R., Charest-Tardif, G., Haddad, S., 2014. Ethanol toxicokinetics resulting from inhalation exposure in human volunteers and 
toxicokinetic modeling. Inhal. Toxicol. 26 (2), 59-69.

Feierman, D.E., Melinkov, Z., Nanji, A.A., 2003. Induction of CYP3A by ethanol in multiple in vitro and in vivo models. Alcohol Clin. Exp. Res. 27 (6), 981-988.

Fjordside, L., Jeppesen, U., Eap, C.B., Powell, K., Baumann, P., Brosen, K., 1999. The stereoseletive metabolism of fluoxetine in poor and extensive metabolizers of sparteine. Pharmacogenetics 9 (1), 55-60.

Flack, S., Nylander-French, L.A., 2012. Occupational chemicals: metabolism, toxicity, and mode of action. Prog. Mol. Biol. Transl. Sci. 112, 163-207.

Glowka, F., Karazniewicz, M., 2007. Enantioselective CE method for pharmacokinetic studies on ibuprofen and its chiral metabolites with reference to genetic polymorphism. Electrophoresis 28 (15), 2726-2737.

Guo, X., Fukushima, T., Li, F., Imai, K., 2002. Determination of fluoxetine enantiomers in rat plasma by pre-column fluorescence derivatization and column-switching high-performance liquid chromatography. Analyst 127 (4), 480-484.

Hamitouche, S., Poupon, J., Dreano, Y., Anet, Y., Lucas, D., 2006. Ethanol oxidation into acetaldehyde by 16 recombinant human cytochrome P450 isoforms:role of CYP2C isoforms in human liver microsomes. Toxicol. Lett. 167, 221-230. Amsterdam.

Hamman, M.A., Thompson, G.A., Hall, S.D., 1997. Regioselective and stereoselective metabolism of ibuprofen by human cytochrome P450 2C. Biochem. Pharmacol 54 (1), 33-41.

Ho, P.C., Ghose, K., Saville, D., Wanwimolruk, S., 2000. Effect of grapefruit on pharmacokinetics and pharmacodynamics of verapamil enantiomers in healthy volunteers. Eur. J. Clin. Pharmacol. 56 (9-10), 693-698.

Holänder, W., 1988. Exposure facilities and aerosol generation and characterization for inhalation experiments. In: Mohr, U. (Ed.), Inhalation Toxicology. SpringerVerlag, New York, pp. 67-85.

Hui, Y., Huang, N.H., Ebbert, L., Bina, H., Chiang, A., Maples, C., Pritt, M., Kern, T. Patel, N., 2007. Pharmacokinetic comparisons of tail-bleeding with cannula or retro-orbital bleeding techniques in rats using six marketed drugs. J. Pharmacol. Toxicol. Methods 56, 256-264. New York.

Hutzler, J.M., Tracy, T.S., 2002. Atypical kinetic profile in drug metabolism reactions. Drug Metab. Dispos. 30 (4), 355-362. Baltimore.

Iber, F.L., 1977. Drug metabolism in heavy consumers of ethyl alcohol. Clin. Pharmacol. Ther. 22, 735-742.

Itoh, T., Maruyama, J., Tsuda, Y., Yamada, H., 1997. Stereoselective pharmacokinetics of ibuprofen in rats: effect of enantiomer- enantiomer interaction in plasma protein binding. Chirality 9, 354-361. New York.

Ingelman-Sunderberg, M., 2001. Implications of polymorphic cytochrome P-450 drug metabolism for drug development. Drug Metab. Dispos. 29 (4), 570-573. Baltimore.

Kaiser, D.G., Vangiessen, G.J., Reischer, R.J., Wechter, W.J., 1976. Isomeric inversion of ibuprofen (R) enantiomer in humans. J. Pharm. Sci. 65, 269-273. New York.

Karin, A., 1996. Enantioselective assays in comparative bioavailability studies of racemic drugs formulation: nice to know or need to know? J. Clin. Pharmacol. 36 (6), 490-499. Stamford.

Kennedy Jr., G.L., Valentine, R., 1994. Inhalation toxicology. In: Hayes, A.W. (Ed.), Principles and Methods of Toxicology, third ed. Raven Press, New York, pp. 805-838.

Klotz, U., Ammon, E., 1998. Clinical and toxicological consequences of the inductive potential of ethanol. Eur. J. Clin. Pharmacol. 54, 7-12. Germany.

Knihinicki, R.D., Williams, K.M., Day, R.O., 1989. Chiral inversion of 2-aryl-propionic acid non-steroidal anti-inflammatory drugs-1. Biochem. Pharmacol. 38, 4389-4395. Oxford.

Kroemer, H.K., Fromm, M.F., Einchelbaum, M., 1996. Stereoselectivity in drug metabolism and action effects of enzyme inhibition and induction. Ther. Drug Monit. 18 (4), 388-392. New York.

Li, D., Han, Y., Meng, X., Sun, X., Yu, Q., Li, Y., Wan, L., Huo, Y., Guo, C., 2010. Effect of organic solvents on rat P450 activities in rat liver microsomes. Drug Metab. Dispos. 38 (11), 1922-1925. Baltimore.

Margolis, J.M., O'Donnel, J.P., Mankowski, D.C., Ekins, S., Obach, R.S., 2000. (R)-, (S)and racemic fluoxetine $\mathrm{N}$-demethylation by human cytochrome P450 enzymes. Drug Metab. Dispos. 28 (10), 1187-1191.
Mateus, F.H., Lepera, J.S., Marques, M.P., Boralli, V.B., Lanchote, V.L., 2007. Simultaneous analysis of the enantiomers of verapamil and norverapamil in rat plasma by liquid chromatography-tandem mass spectrometry. J. Pharm. Biomed. Anal. 45 (5), 762-768.

Mehvar, R., Reynolds, J., 1996. Reversal of stereoselectivity in the hepatic availability of verapamil in isolated perfused rat livers. Drug Metab. Dipos. 24 (10), 1089-1094. Baltimore.

Miners, J.O., Birkett, D.J., 1998. Cytochrome P4502C9: an enzyme of major importance in human drug metabolism. Br. J. Clin. Pharmacol. 45 (6), 525-538.

Newa, M., Bhandari, K.H., Kim, J.O., Im, J.S., Kim, J.A., Yoo, B.K., Woo, J.S., Choi, H.G., Yong, C.S., 2008. Enhancement of solubility, dissolution and bioavailability of ibuprofen in solid dispersion systems. Chem. Pharm. Bull. 56 (4), 569-574. Tokyo.

Niosh Manual of Analytical Methods. 1400 Alcohols I, fourth ed., 1994 Available at: http://www.cdc.gov/niosh/docs/2003-154/pdfs/1400.pdf Accessed in November, 262014.

Pastino, G.M., Asgharian, B., Roberts, K., Medinsky, M.A., Bond, J.A., 1997. A comparison of physiologically based pharmacokinetic model predictions and experimental data for inhaled ethanol in male and female B6C3F1 mice, F344 rats, and humans. Toxicol. Appl. Pharmacol. 145, 147-157.

Ring, B.J., Eckstein, J.A., Gillespie, J.S., Binkley, S.N., Vandenbranden, M., Wrighton, S.A., 2001. Identification of the human cytochromes P450 responsible for in vitro formation of R- and S-norfluoxetine. J. Pharmacol. Exp. Ther. 297, 1044-1050. Baltimore.

Ritschel, W.A., Kearns, G.L., 1998. Handbook of Basic Pharmacokinetics-including Clinical Applications, fifth ed. An Apha Handbook, Washington, p. 562.

Robinson, M.A., Mehvar, R., 1996. Enantioselective distribution of verapamil and norverapamil into human and rat erythrocytes: the role of plasma proteína binding. Biopharm. Drug Dispos. 17, 577-587. Chichester.

Rokitta, D., Pfeiffer, K., Streich, C., Gerwin, H., Fuhr, U., 2013. The effect of organic solvents on enzyme kinetic parameters of human CYP3A4 and CYP1A2 in vitro. Toxicol. Mech. Methods 34, 576-583.

Rudy, A.C., Knight, P.M., Brater, D.C., Hall, S.D., 1991. Stereoselective metabolism of ibuprofen in humans: administration of R-, S- and racemic ibuprofen. J. Pharmacol. Exp. Ther. 259, 1133-1139. Bethesda.

Sandor, P., Sellers, E.M., Dumbrell, M., Khouw, V., 1981. Effect of short- and longterm alcohol use on phenytoin kinetics in chronic alcoholics. Clin. Pharmacol. Ther. 30, 390-397.

Sattari, S., Jamali, F., 1994. Evidence of absorption rate dependency of ibuprofen in the rat. Chirality 6 (5), 435-439.

Teng, X.W., Wang, S.W.J., Davies, N.M., 2003. Stereospecific high-performance liquid chromatographic analysis of ibuprofen in rat serum. J. Chromatogr. B 796, 225-231. Amsterdam.

Tornio, A., Niemi, M., Neuvonen, P.J., Backman, J.T., 2007. Stereoselective interaction between the CYP2C8 inhibitor gemfibrozil and racemic ibuprofen. Eur. J. Clin. Pharmacol. 63 (5), 463-469.

Tracy, T.S., Korzekwa, K.R., Gonzalez, F.J., Wainer, I.W., 1999. Cytochrome P450 isoforms involved in metabolism of the enantiomers of verapamil and norverapamil. Br. J. Clin. Pharmacol. 47 (5), 545-552.

Upreti, V., Eddington, N.D., 2007. Fluoxetine pretreatment effects pharmacokinetics of 3,4-methylenedioxymethamphetamine (Mdma, ECSTASY) in rat. J. Pharm. Sci. 97, 1593-1605. New York.

Vuppugalla, R., Chang, S.Y., Zhang, H., Marathe, P.H., Rodrigues, D.A., 2007. Effect of commonly used organic solvents on the kinetics of cytochrome P450 2B6- and 2C8-dependent activity in human liver microsomes. Drug Metab. Dispos. 35 (11), 1990-1995.

Wong, D.T., Bymaster, F.P., Reid, L.R., Fuller, R.W., Perry, K.W., 1985. Inhibition of serotonin uptake by optical isomers of fluoxetine. Drug Dev. Res. 6, 397-403. New York.

Zerilli, A., Lucas, D., Amet, Y., Beauge, F., Volant, A., Floch, H.H., Berthou, F., Menez, J.F., 1995. Cytochrome P-450 2E1 in rat liver, kidney and lung microsomes after chronic administration of ethanol either orally or by inhalation. Alcohol Alcohol 30 (3), 357-365. 